2021, Volume 16, ATEE 2020 - Winter Conference. Teacher Education for Promoting WellBeing in School. Suceava, 2020, pages: 54-69 | https://doi.org/10.18662/lumproc/atee2020/04

\section{Psychological Features of the Tolerance of Future Specialists in Socionomic Professions}

\section{Hanna BARABASHCHUK ${ }^{1}$ Mariana DUSHKEVYCH ${ }^{2}$ Natalia HUTSULIAK ${ }^{3}$ \\ ${ }^{1}$ Candidate of Psychological Sciences, Yuriy Fedkovych Chernivtsi National University, Chernivtsi, Ukraine h.barabashchuk@,chnu.edu.ua}

${ }^{2}$ Candidate of Psychological Sciences, Yuriy Fedkovych Chernivtsi National University, Chernivtsi, Ukraine m.kornivska@,chnu.edu.ua

${ }^{3}$ Candidate of Psychological Sciences, Yuriy Fedkovych Chernivtsi National University, Chernivtsi, Ukraine n.guzulyak@chnu.edu.ua
Abstract: It is a set on the basis of theoretical researchers, that the modern specialist of the sphere of "Man-Man», except the certain volume of professional abilities and knowledge, must own personality-mature qualities: to show readiness for self-development and self-perfection; make a decision on their own; have their own system of values and be able to correlate their own vital persuasions with the senses and stereotypes of society. For this reason, development of their tolerance as a constituent of professionalism is important in the professional preparation of specialists of socio-economic professions.

Tolerance is not just a tolerance for others' thoughts, beliefs and behaviour, it is a purposeful effort on the part of the individual to create an information space that promotes harmony, interpersonal cooperation, emotional tact and respect.

The empirical study involved 40 second-year students, including psychology students and foreign language teachers. The psychodiagnostic complex of methods presented in the article made it possible to obtain reliable research results. A comparative analysis of respondents indicators showed that «tolerance» as a personal quality is significant for both groups. It is stated that psychology students are more tolerant of representatives of different social strata, while foreign language students are tolerant of ethnic minorities.

The study found that future psychologists seeking to assert their beliefs and considerations, if the situation becomes conflictual, can be harsh. Future teachers are more critical of themselves and their opinions, showing tact and understanding to manifest «paradoxical» actions, even if they do not agree with them.

The overall tolerance index of the two groups under study indicates that their behaviour and attitudes towards the world, people and events will depend on the particular social situation they are currently in.

Keywords: tolerance, future teacher, professional formation, students

How to cite: Barabashchuk, H., Dushkevych, M., \& Hutsuliak, N. (2021). Psychological Features of the Tolerance of Future Specialists in Socionomic Professions. In O. Clipa (vol. ed.), Lumen Proceedings: Vol. 16. ATEE 2020 - Winter Conference. Teacher Education for Promoting Well-Being in School. Suceava, 2020 (pp. 54-69). Iasi, Romania: LUMEN Publishing House. https:/ /doi.org/10.18662/lumproc/atee2020/04 


\section{Introduction}

In recent years, the growing pace of the development of Ukrainian society and the transformation of social ideals and values have inevitably led to changes in personal structures of an individual, setting new parameters for the professionalization of the individual. The emergence of new goals and values in the educational space has caused a need not only for educated but, above all, competent and highly cultured professionals, capable of reflecting a positive and professional worldview, doing a successful and professional activity in complex and contradictory situations of interpersonal interactions.

The state educational standard of higher professional education of a new generation emphasizes the importance of developing the cultural potential of the future specialist in socionomic professions.

The professional activity of specialists in socionomic professions involves a constant work with people and a direct communication with them. The peculiarity of the activity of specialists in this field is determined by the fact that the main subject of the activity is the specialist himself, with inherent personal qualities, abilities and work experience (Isaev, 2013). That is why we see that in the conditions of the professional training of specialists in socionomic professions it is important to put an emphasis on the formation and development of their tolerance as a constituent of personal and professional self-realization.

\section{Literature review}

Today, the phenomenon of tolerance is the subject of the wide range of scientific researches. Tolerance is particularly interesting as a personal tool in interpersonal relationships, especially among professionals working in «Man - Man» field. It can be stated that tolerance is one of the key components of the professional suitability of an expert in socionomic field, and the formation of this ability is an integral part of mastering these professions. By their nature future professionals are obliged to interact constructively with people, and tolerance is not only a personal necessity, but also the norm of professional activity for them. 
According to Shalin (2002): "tolerance is when you are being tolerant of other people's thoughts, beliefs and behavior. It is respect or recognition of the equality of others, refusal of domination or violence. In other words, these are constant and purposeful efforts to create such an information field that would cultivate people's and society's attitude towards self-restraint, harmony and cooperation, emotional mobilization and understanding of cultures". Comprehending the basics of tolerance and harmonizing oneself and one's life, a person gets rid of the causes of aggression, fear and anxiety. As a consequence, a tolerant person is international by his/her own essence, tolerant of others and good-natured (Stefanenko, 1999).

It is essential to note that scientists have a deep interest in the outlined issues. Thus, tolerance has been researched as a personal formation of students in conditions of professional development and studying at university (Falko, 2009; Neizhpapa, 2015); the features of tolerance of specialists, who interact with people with special educational needs, have been illuminated (Burlakova, 2010); as well as people with social (Gutu \& Boghian, 2019; Sikorska et al., 2017) and cultural peculiarities (Hryva, 2007; Onufriieva, 2012).

Tolerance as the intrapersonal characteristic of the specialist in socionomic field is formed gradually, under the influence of sociopsychological factors, which are determined by the conditions of the professional development and individual characteristics.

Professional development involves the use of techniques of social influence on the individual, his/her involvement into various activities aimed at forming a system of professionally important qualities. Professionally important qualities of the specialist often determine the productivity of the person's activity and, consequently, contribute to his/her successful professional development.

Summarizing the analysis of the personal components of specialist professional development, Zeer (2008) identifies four main factors:

$>$ professionally important psychophysiological attributes (visualmotor coordination, hand-eye coordination, neuroticism, extraversion, reactivity, energy), the development of which occurs in the process of mastering the activity; 
$>$ the orientation of the individual, characterized by the system of dominant needs, motives, attitudes, values and directives;

$>$ professionally important psychological qualities of the individual that determine productivity of the activity;

$>$ professional competence as a set of professional knowledge, skills and methods of performing professional activity.

Psychological factors of the professional development of the individual are in some way combined with such a concept as «professional suitability», which is defined as a measure of compliance of the person's qualities with current requirements of the activity, as well as his/her ability to perform respective job functions at present. It is important to talk about professional suitability among specialists in socionomic field, because their activity presupposes the presence of certain predispositions, abilities and professionally significant qualities. Among general predispositions are: positive perception of the world; altruistic orientation; desire to work with people and for people; the ability to hear and listen to the interlocutor, as well as to clearly and consistently express your own thoughts, the ability to get acquainted and communicate with new people; desire and predisposition to organize other people's activities, etc. Among professionally significant qualities we can outline: sensitivity, attentiveness, emotional stability, tolerance, flexibility, empathy, observation, decision-making speed, organizational and communicative abilities.

Socionomic professions are characterized by the lack of strict and uniform requirements for the results of work and the very process of professional activity. At the same time, there are special requirements for the representatives of these professions, because the object of the work is other people, so the professional functions acquire some certain specificity. Kaverina (1978) thinks that it is necessary to consider the estimation of social objects condition as the basic and the most important function of the worker in "Man-Man" professions; people management; teaching; education; information, social and medical services for people.

In the context of socionomic professions, a special type of interaction is allowed, the so-called "helping behavior". As Rogers (1994) noted "helping relationships" are those in which at least one party intends to 
assist the other party in terms of personal growth, development, better life and the ability to interact with others. The peculiarity of socionomic professions is that "helping activity" becomes the main element of professional activity. That is, unstructured help becomes structured, and the subject of such activities begins to consciously and purposefully apply special knowledge and skills.

According to Burlakova (2010), the basic characteristic and the foundation of socionomic professions is prosocial activity of the individual, which originates in everyday life, but successfully changes due to the motives of the professional activity of the specialist.

In numerous studies on the professional qualities of the specialists in socionomic professions, tolerance takes a prominent place, which determines not only professional success, but also self-realization of the future specialist. Skrypnyk (2010) points out that tolerance in the activities of the specialists in socionomic field should be considered as respect for differences and as a balanced response to them.

According to Druzhynina (2012), this issue is especially relevant at the stage of the professional development of the students in socionomic field, as in this period understanding attitude towards others is developed and professional self-determination is motivated.

In conditions of educational and professional activities students have an opportunity to develop tolerance and acquire such personal qualities as tolerance, compassion, acceptance of others, empathy, sensitivity, understanding of other people's psychological states, the need to communicate and help others.

Burlakova (2010) points out that tolerance is a professional quality of a teacher and psychologist. Tolerance as a personal feature of these specialists is especially relevant in the situations of differences in estimates, beliefs, behavior of people. It is also manifested in reducing sensitivity to those having distinctive features by involving mechanisms of patience, endurance and self-control.

Boluchevskaya (2010) draws an interesting conclusion. Having conducted the research, she states that students in socionomic field focus more on altruism and tolerance, and this focus is more expressed than the 
focus on selfishness. According to the author, this indicates an inner willingness to help people and a smaller focus on social status and financial reward.

The presented review of the literature does not clarify all the issues of the researched problems. In particular, the question of whether specialists in socionomic field are equally tolerant remains open.

\section{Aim of research}

The aim of the study is the empirical identification of tolerance features of future specialists in socionomic professions in conditions of professional development.

\section{Research methods}

\subsection{Participants}

The study involved 40 respondents in socionomic field, 20 of them are future psychologists and other 20 -future foreign language teachers. When the study was being carried out (in autumn 2019), the respondents were full-time students in their second year of studies at Yuriy Fedkovych Chernivtsi National University.

The research procedure was established in compliance with all the requirements of psychodiagnostic examination. Before the beginning of the research, its purpose was explained to students. They were also informed that their results would be anonymous and confidential, and could be reported at their personal request.

\subsection{Methods}

$>$ Express-questionnaire Tolerance Index (Soldatova \& Shaiherova, 2003)

This technique is used to diagnose the general level of tolerance. The methodology includes statements that show attitude towards certain social groups (national minorities, people with mental problems, the poor) and communicative directives (respect for the opinion of opponents, willingness to constructively resolve conflicts and productive cooperation). The 
advantage and informativeness of the methodology is the separation of subscales: "ethnic tolerance"; "social tolerance" and "tolerance as a personal trait".

Communicative Tolerance Questionnaire (Boiko, 1996)

This technique makes it possible to diagnose the strong and weak points of the communicative process, understand which behavioral responses, strategies and attitudes of the interpersonal communication should be adjusted in order to make the communication process enjoyable and effective for each party. At the same time, tolerance in communication is an important characteristic in professional activities of the future specialist.

$>$ Express-test How tolerant you are ('Tushkanova, 2002)

The proposed express-test is quite convenient, as with a small number of questions you can monitor subject's tolerance display in interpersonal interactions.

$>$ Statistical Methods

Mathematical and statistical processing of the research results was performed using statistical data analysis packages STATISTICA 6.0 for Windows. In particular, Student's t-test was used to compare the average sets of two independent samples.

\section{Results and Discussions}

At the first stage of our research, it was necessary to find out how students, who have chosen a profession in socionomic field, show their attitude to the world around them and other people, and by what social norms they are guided in interpersonal interactions.

The study demonstrates that the vast majority of students $(80 \%)$ (see Fig. 1), who will work with people in the future, are characterized by the average level of tolerance. Such respondents demonstrate a combination of tolerant and intolerant qualities, that is, their attitude to others and behavior will be determined primarily by the specific social situation in which they will find themselves. $15 \%$ of the interviewed students demonstrated a high level of tolerance, which proves their personal maturity and self-sufficiency. They 
are able to interact with people who have some distinctive features and are ready to accept the position of others without judgement and criticism.

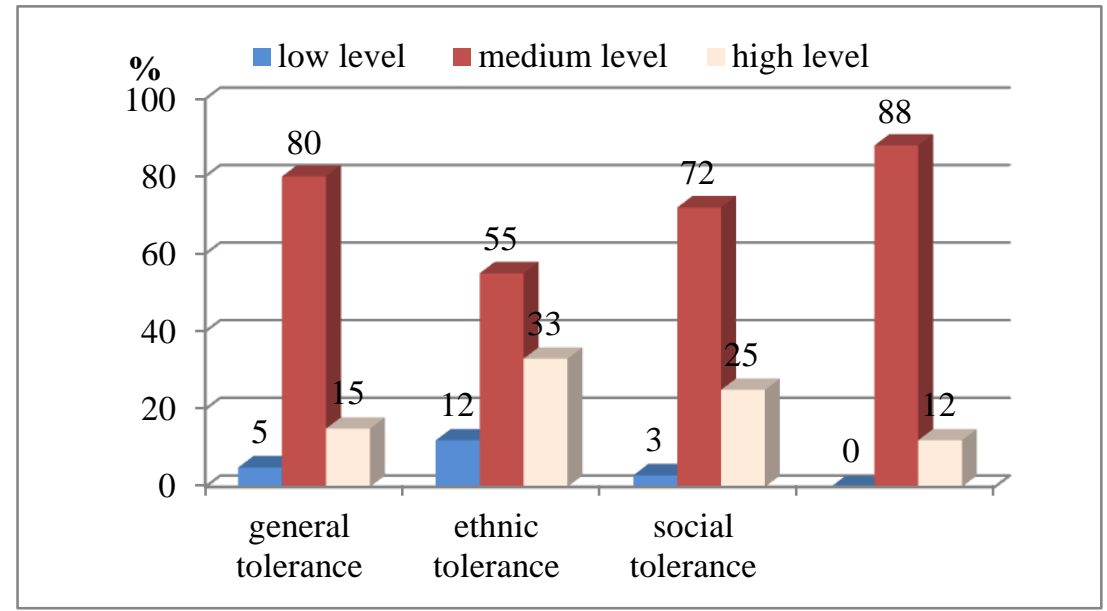

Fig. 1. Percentage division of the students in socionomic field by the level of tolerance (general group)

Source: Authors own contribution

At the same time, $5 \%$ of the respondents have a low level of tolerance, which indicates their tendency to have intolerant attitudes towards the world and other people. Such clearly manifested intolerance is obviously conditioned by certain intrapersonal conflicts and the unwillingness of the individual to know the reality around us, as well as the unwillingness to understand the motives of other people's actions. The behavior of such specialists can be categorical, and it is quite difficult for them to accept views and positions that do not correspond to their own.

The analysis of the results on the scale «ethnic tolerance» allows to find out the attitude of the future specialist towards the representatives of other ethnic groups and directives related to intercultural interaction. Students in socionomic field are positively oriented towards the representatives of other ethnic groups, as 55\% of respondents have a medium level of tolerance and $33 \%$ h have a high level of tolerance. However, in real interactions with the representatives of different national minorities they will remain cautious, while $12 \%$ of respondents are completely unprepared to interact with other ethnic groups. 
On the scale «social tolerance» it was found that $72 \%$ of respondents are quite tolerant of various social groups (minorities, criminals, people with mental problems) and of social processes occurring in society, while $3 \%$ of respondents demonstrate intolerance.

It should be noted that on the scale «tolerance as a personal trait» $88 \%$ of students in socionomic field were diagnosed with the average level of manifestation of this characteristic, and $12 \%$ of students with the high level. A significant percentage of the average level indicates that students are quite tolerant of the events and reality around us. They use such personal qualities as understanding, acceptance and compassion. However, in some situations they are ready to change their beliefs and directives, if it directly affects their future and life, that is why they can even be confrontational and uncompromising.

Having made the comparative analysis of the results between the researched groups of students, there were not found any significant differences, but the frequency distribution is slightly different. As it is shown in Table 1, certain differences are observed on the scales «ethnic tolerance» and «social tolerance», while on the last scale «tolerance as a personal trait» the results of the researched groups are similar.

Thus, in the context of the ethnic aspect students in foreign language teacher education major are more tolerant than students in psychology major. Ethnic tolerance of the individual is manifested in various critical situations of interpersonal and intrapersonal choice. It is obvious that students in foreign language teacher education major have wider experience of communicating with the representatives of other countries, so they understand how difficult it is not only to adapt to another socio-cultural space, but also to accept stereotypes, norms and beliefs of another ethnic group. In our point of view, the realization of ethnic tolerance occurs when individuals directly find themselves in the conflict situation of interaction with the members of other ethnic groups, when the considerations, which individuals can make, correlate. That is exactly what they can deny, because it does not correspond to their personal and life beliefs. 
Table 1. Percentage division of the students in socionomic field by the subscales of tolerance

\begin{tabular}{cccc}
\hline Scales & Level & $\begin{array}{c}\text { Students in } \\
\text { psychology major }\end{array}$ & $\begin{array}{c}\text { Students in foreign } \\
\text { language teacher } \\
\text { education major }\end{array}$ \\
\hline Ethnic & High & 25 & 25 \\
tolerance & Medium & 50 & 75 \\
\hline Social & Low & 25 & 0 \\
tolerance & High & 20 & 10 \\
\hline Tolerance & Low & 80 & 75 \\
as a & High & 0 & 15 \\
personal & Medium & 20 & 85 \\
trait & Low & 80 & 0 \\
\hline
\end{tabular}

At the same time, during educational activities the importance of the practical work with people of different social status is repeatedly emphasized to students in psychology major. In particular, with those people, who do not meet generally accepted society norms due to their own low stress resistance and the lack of internal resources to overcome critical situations, and those who belong to the so-called "risk group". For students in foreign language teacher education major the issues of social stratification of society are less topical, so it is likely that their choice of answers is conditioned by the subjective attitude towards a particular issue.

Speaking about tolerance as a personal trait, the results of the researched groups coincide, which only confirms the priority of «tolerance» as one of the professionally important qualities of the future specialist in «Man-Man» profession. In particular, $20 \%$ of the interviewed future psychologists have identified that they possess a high level of this trait, while in the group of future teachers only $15 \%$ of respondents have identified it. However, the average level of tolerance display as of a personal trait is observed in $85 \%$ of students in foreign language teacher education major and in $80 \%$ of students in psychology major.

Tolerance or intolerance is most frequently manifested in the behavior and sayings of the individual, that is, in communication and interaction with others. 
Communicative tolerance is manifested in the ability to get along with different people in different situations; in the ability to find an individual approach to people; in the ability to restrain oneself in relationships with people; in the ability to show tolerance and ease in communication. Boiko (1996) notes that the immaturity of communicative tolerance and negative communicative attitude are expressed in behavioral reactions, such as being reserved and openly cruel to people; tendency to make unreasonable generalizations of negative facts in relationships with communication partners and observation of social activities.

According to the results of the research by means of Communicative Tolerance method, students in socionomic field are ready to accept communication partners, showing tolerance and objectivity, as well as desire to constructively resolve conflicting or contradictory situations of the interaction.

The detailed analysis of the results has shown that $70 \%$ of students in psychology major are characterized by a high level of communicative tolerance, while the corresponding level has been found among $50 \%$ of the interviewed students in foreign language teacher education major (fig.2).

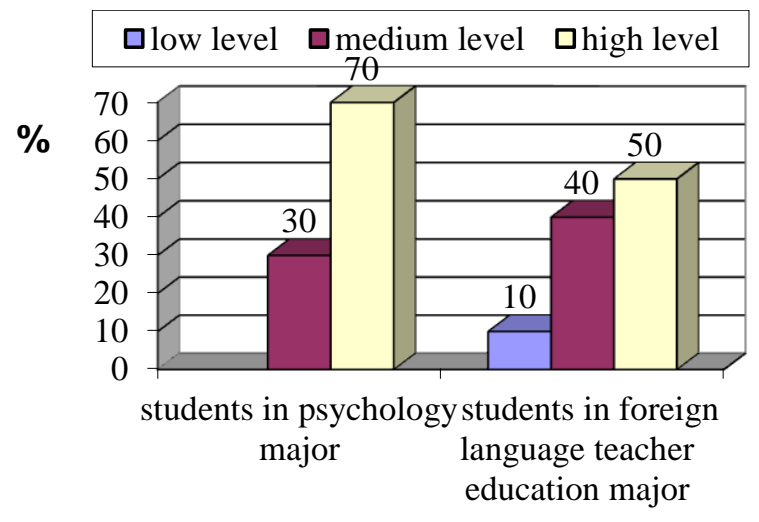

Fig.2. The correlation of the levels of communicative tolerance display of the students in socionomic field (Source: Authors own contribution)

The high level of tolerance is characterized by the ability to establish effective interpersonal interaction, maintain a significant number of contacts 
and find positive results in each of them, have patience and desire to understand and listen to the interlocutor.

Speaking about the average level of communicative tolerance, $30 \%$ of students in psychology major have been found with it, as for students in foreign language teacher education major - 40\%. The medium level is characterized by normal (equal) relationships with others, the ability to establish and maintain effective interaction, to interact with others holding a dialogue, partnership, patience and understanding. It has also been noted that $10 \%$ of students in foreign language teacher education major demonstrate communicative intolerance.

The following diagnostic technique allows to characterize separate scales, which together represent the general level of communicative tolerance. The analysis of each separate communicative tolerance characteristic is in the range from 0 to 15. That is why, when it reaches up to 5 points, it is the high level of tolerance regarding the manifestation of a certain trait. When it reaches 15 points, it is complete intolerance then.

Table 2. Average group numbers of students in socionomic field on the scales of communicative tolerance

\begin{tabular}{llcc}
\hline No & $\begin{array}{l}\text { Separate communicative tolerance } \\
\text { characteristics }\end{array}$ & $\begin{array}{c}\text { Students in } \\
\text { psychology } \\
\text { major }\end{array}$ & $\begin{array}{c}\text { Students in } \\
\text { foreign language } \\
\text { teacher } \\
\text { education major }\end{array}$ \\
\hline 1 & $\begin{array}{l}\text { Rejection or poor understanding of } \\
\text { another person's personality }\end{array}$ & 4,6 & 5,3 \\
$\quad \begin{array}{l}\text { Using yourself as an ideal in evaluating, } \\
\text { behaving, and directing other people's } \\
\text { thoughts }\end{array}$ & 3,5 & $5,1 *$ \\
3 & $\begin{array}{l}\text { Sharpness or conservatism in other } \\
\text { people's evaluations }\end{array}$ & 5,1 & 5,7 \\
4 & $\begin{array}{l}\text { Inability to hide or suppress unpleasant } \\
\text { feelings when facing uncommunicative } \\
\text { qualities of partners } \\
\text { Desire to re-educate partners } \\
\text { Desire to change the partner for your } \\
\text { own sake, so that he/she complies with } \\
\text { your standards } \\
\text { Inability to forgive the mistakes of others, } \\
\text { unintentionally caused troubles and their } \\
\text { shyness }\end{array}$ & 5,3 & 5,1 \\
\hline
\end{tabular}




\begin{tabular}{llcc}
\hline 8 & $\begin{array}{l}\text { Intolerance of physical or mental } \\
\text { discomfort created by other people }\end{array}$ & 3,1 & 4,2 \\
9 & $\begin{array}{l}\text { Inability to adapt to the character, habits } \\
\text { and desires of others }\end{array}$ & 4,6 & 4,4 \\
10 & $\begin{array}{l}\text { The overall score of communicative } \\
\text { tolerance }\end{array}$ & 42,3 & 43,6 \\
\hline
\end{tabular}

Note: * tendency for a significant difference when $\mathrm{p} \leq 0.08$ (by Student's $t$-test)

In general, as it is shown in Table 2, respondents, who associate their future professional activities with people, are quite tolerant of interaction in interpersonal communication. Thus, their behavioral manifestations are based on the ease of accepting the individual characteristics of another person, they are less categorical about their own views and do not evaluate the behavior, way of thinking or individual characteristics of people as the ideal of themselves. Instead, the interviewed correlate, study and try to understand the individual characteristics of others, respect character, habits of people with whom they communicate, distinguish their own demands and are not ready to adjust interpersonal contacts to their own needs or standards.

The final stage of our study was to analyze the respondents' tolerance level. The comparative analysis of the respondents' results shows that there is a significant difference between the interviewed $(\mathrm{p} \leq 0,001$, temp $=4,49)$. The average group result among students in foreign language teacher education major is $12 \pm 0,52$ points, while the result in the group of students in psychology major is $9,25 \pm 0,44$ points. The obtained result allows us to state that future teachers tend to be more tolerant of the interlocutor and are willing to give up their own views.

$70 \%$ of students in foreign language teacher education major are characterized by a high level of communicative tolerance, while the corresponding level has been found among $20 \%$ of the interviewed students in psychology major. Thus, students in foreign language teacher education major are more critical of themselves and their reasoning, show tactfulness and understanding of the manifestation of «paradoxical» actions of others, have more flexible thinking and prudence. 


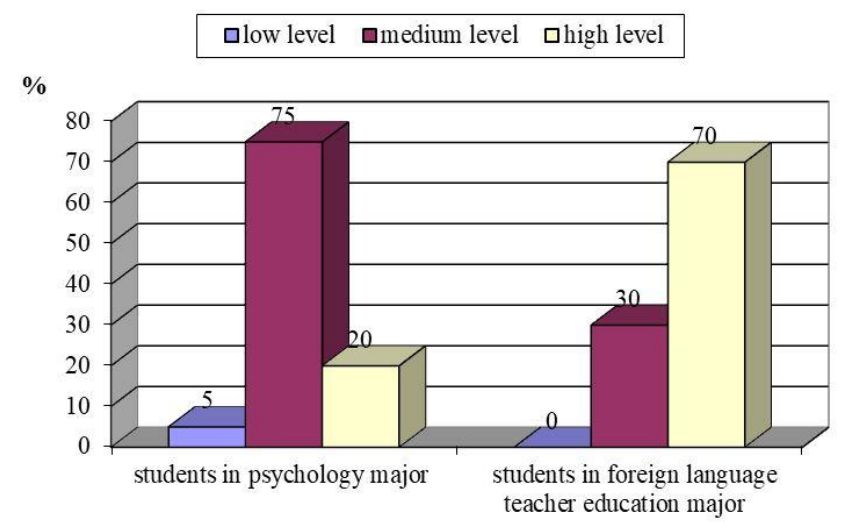

Fig.3. Percentage division of the students in socionomic field by the level of tolerance

(Source: Authors own contribution)

The researched students with the average level of tolerance $75 \%$ of students in psychology major and 30\% of students in foreign language teacher education major) are characterized by the fact that they endeavor to defend their beliefs, engage in dialogue and express their views. In conflict situations, they can be harsh and disrespectful to others. If the interlocutor is emotionally weaker, then they can dominate during the interaction process in order to achieve the desired result. It is essential to note that $5 \%$ of the interviewed students in psychology major are firmly convinced and obstinate, tend to persistently impose their views on other people, which often leads to misunderstandings and emotional tension in interaction.

\section{Conclusions}

Basing on the processed theoretical and empirical data, we can conclude that the professional development of the specialists in socionomic professions demands consideration of sociogenic nature of the future activities and requires purposeful development of the tolerant attitude towards the subject of interaction. The result of the tolerance development at the stage of professional training is the formation of personal preparedness and inner tolerance of something that is distinctive from yours. 
In general, future teachers and psychologists are oriented to show tolerance in interaction with other people. In particular, social tolerance is more acceptable for them in comparison with ethnic tolerance. The level of tolerance manifestation may change if the situation in which they find themselves requires it.

While communicating with others, students in psychology major and students in foreign language teacher education major try to accept other people's individual characteristics, forgive their mistakes, tackle problems and reach compromises. However, future teachers can evaluate other people's behavior basing on their own standards.

Students in foreign language teacher education major are more tactful while stating their beliefs and are critical of their own thoughts and views. Students in psychology major withstand the stress of conflict situations and are ready to defend their position even when they deal with authority figures.

\section{Prospects for further research}

As a promising research we consider a thorough research of tolerance in the professional development of specialists in socionomic field, which will help optimize the processes of professionalization and personal growth of the future specialist in the process of mastering a particular profession, taking into account reforming the educational system and current needs.

\section{References}

Boiko, V. V. (1996). The energy of emotions in communication: a look at oneself and others. Moscow Filin information and publishing house.

Boluchevskaya, V. V. (2010). Professional self-determination of future professionals in assisting professions. Volgograd.

Burlakova, L. V. (2010). Determination of the class of socionomic professions. Practical psychology and social work, 7, 68-73.

Druzhynina, I. A. (2012). Research of the professional component in the structure of the identity of students in psychology major. Psychological perspectives, 19, 91-101. 
Falko, N. M. (2009). Psychological bases of students' internality formation in psychological and pedagogical majors at university. Science and education, 8 , 176-180.

https://scienceandeducation.pdpu.edu.ua/doc/2009/8 2009/40.pdf.pdf

Gutu, V., \& Boghian, I. (2019). A Bidimensional Psycho-pedagogical Model for Tolerance Education. Revista Romaneasca pentru Educatie Multidimensionala, 11(4), 1-16. https://doi.org/10.18662/ rrem/153

Hryva, O. A. (2007). Tolerance in multicultural environment. Kyiv.

Isaev, V. P. (2013). Psychological peculiarities of the future professional activity of the specialists in socionomic field. The world of science, culture, education, 4(41), 203-206.

Kaverina, R. D. (1978). Psychological classification experience of some professions for professional consultation. Psychology questions, 2, 64-72.

Neizhpapa, L. S. (2015). Professional orientation of the future social pedagogue as a condition of his professional self-determination. Social work. Social pedagogy, $11,79-86$.

Onufriieva, L. A. (2012). Peculiarities of professional culture development of future specialists in socionomic professions as a goal of professional formation. Problems and prospects of formation of innovative system of education in the XXI century, 20-21.

Rogers, C. (1994). A look at the psychotherapy. Human development. Universal.

Shalin, V. V. (2002). Education and tolerance culture formation. Journal History, 11, 8-10.

Sikorska, L. B., Vovk, L. P., \& Volotovska, Y. V. (2017). Psychological conditions of stress resistance of future specialists of the special education system. Young scientist, 5, 223-226. http://nbuv.gov.ua/UJRN/molv 2017 554

Skrypnyk, M. M. (2010). Theoretical approaches to the definition of the term "tolerance". Problems of general and pedagogical psychology, 12(5), 306-309.

Soldatova, H. U., \& Shaiherova L. A. (2003). Workshop on psychodiagnostics and tolerance research. Moscow.

Stefanenko, T. H. (1999). Ethnopsychology. Aspect-Press.

Tushkanova, O. (2002). How tolerant are you? // Tolerant consciousness and the formation of tolerant relations (theory and practice): collection of articles, 357-359.

Zeer, E. F. (2008). Psychology of the professional self-determination in early youth. Voronezh. MODEK. 